\title{
A split-GFP tool reveals differences in the sub-mitochondrial distribution of wt and mutant alpha-synuclein
}

\author{
Mattia Vicario ${ }^{1}$, Domenico Cieri ${ }^{1}$, Francesca Vallese ${ }^{1}$, Cristina Catoni ${ }^{2}$, Lucia Barazzuol ${ }^{1}$, Paola Berto',

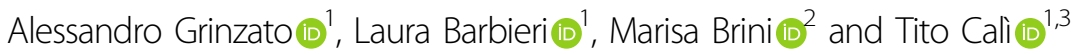

\begin{abstract}
Parkinson's disease (PD), the second most common neurodegenerative disorder, is characterized by dopaminergic neuronal loss that initiates in the substantia nigra pars compacta and by the formation of intracellular inclusions mainly constituted by aberrant a-synuclein (a-syn) deposits known as Lewy bodies. Most cases of PD are sporadic, but about $10 \%$ are familial, among them those caused by mutations in SNCA gene have an autosomal dominant transmission. SNCA encodes a-syn, a small 140-amino acids protein that, under physiological conditions, is mainly localized at the presynaptic terminals. It is prevalently cytosolic, but its presence has been reported in the nucleus, in the mitochondria and, more recently, in the mitochondria-associated ER membranes (MAMs). Whether different cellular localizations may reflect specific a-syn activities is presently unclear and its action at mitochondrial level is still a matter of debate. Mounting evidence supports a role for a-syn in several mitochondria-derived activities, among which maintenance of mitochondrial morphology and modulation of complex I and ATP synthase activity. a-syn has been proposed to localize at the outer membrane (OMM), in the intermembrane space (IMS), at the inner membrane (IMM) and in the mitochondrial matrix, but a clear and comparative analysis of the sub-mitochondrial localization of WT and mutant asyn is missing. Furthermore, the reasons for this spread sub-mitochondrial localization under physiological and pathological circumstances remain elusive. In this context, we decided to selectively monitor the sub-mitochondrial distribution of the WT and PD-related a-syn mutants A53T and A30P by taking advantage from a bimolecular fluorescence complementation (BiFC) approach. We also investigated whether cell stress could trigger a-syn translocation within the different mitochondrial sub-compartments and whether PD-related mutations could impinge on it. Interestingly, the artificial targeting of a-syn WT (but not of the mutants) to the mitochondrial matrix impacts on ATP production, suggesting a potential role within this compartment.
\end{abstract}

\section{Introduction}

Parkinson's disease (PD) affects 6 million individuals worldwide. The neuronal loss in the substantia nigra pars compacta $^{1}$ and the formation of intracellular inclusions of

\footnotetext{
Correspondence: Marisa Brini (marisa.brini@unipd.it) or Tito Calì (tito. cali@unipd.it)

${ }^{1}$ Department of Biomedical Sciences, University of Padova, Padova, Italy

${ }^{2}$ Department of Biology, University of Padova, Padova, Italy

Full list of author information is available at the end of the article.

These authors contributed equally: Mattia Vicario, Domenico Cieri, Francesca Vallese

Edited by P.G. Mastroberardino
}

aberrant $\alpha$-synuclein $(\alpha \text {-syn })^{2}$, whose autosomal dominant mutations $s^{3}$ are found in familial forms of the disease, are the main hallmarks. Mounting evidence indicates that $\alpha$ syn regulates vesicles release at the synaptic level and stabilizes the assembly of SNARE complex ${ }^{4-7}$. Although prevalently cytosolic, $\alpha$-syn can also be found in the nucleus $^{8-11}$, in the mitochondria ${ }^{12-17}$ and in the mitochondria-associated ER membranes (MAMs) fraction $^{18,19}$. Its close relationship with mitochondria has been extensively supported by convincing works showing altered mitochondrial functions and dynamics in different

\section{(c) The Author(s) 2019}

(c) (i) Open Access This article is licensed under a Creative Commons Attribution 4.0 International License, which permits use, sharing, adaptation, distribution and reproduction cc) in any medium or format, as long as you give appropriate credit to the original author(s) and the source, provide a link to the Creative Commons license, and indicate if changes were made. The images or other third party material in this article are included in the article's Creative Commons license, unless indicated otherwise in a credit line to the material. If material is not included in the article's Creative Commons license and your intended use is not permitted by statutory regulation or exceeds the permitted use, you will need to obtain permission directly from the copyright holder. To view a copy of this license, visit http://creativecommons.org/licenses/by/4.0/. 
cellular and animal models where the expression level of $\alpha$-syn was manipulated by overexpression and/or silencing and where $\alpha$-syn mutants were introduced. Accumulation of WT $\alpha$-syn causes a reduction in mitochondrial complex I activity ${ }^{14,20-22}$ while $\alpha$-syn null mice display striking resistance to the neurotoxin 1methyl-4-phenyl-1,2,3,6-tetrahydropyridine (MPTP)induced degeneration of dopaminergic neurons and reduced dopamine release ${ }^{23,24}$. Alterations including increased oxidative stress, lipid abnormalities, complex I deficiency, increased mitochondrial fragmentation, loss of membrane potential and cytochrome c release were reported in mutant $\alpha$-syn transgenic ${ }^{25,26}$ and null mice ${ }^{27}$, as well as in cells overexpressing wt $\alpha$-syn ${ }^{28}$. Moreover, $\alpha$ syn has been shown to participate in the maintenance of mitochondrial integrity by regulating the fission/fusion machinery and the autophagic process ${ }^{18,29-31}$. Finally, we have previously demonstrated that $\alpha$-syn positively enhanced mitochondrial $\mathrm{Ca}^{2+}$ transients generated upon $\mathrm{Ca}^{2+}$ release from the endoplasmic reticulum (ER) by increasing the ER-mitochondria contact sites ${ }^{32}$. A dosedependent mechanism of this action has been proposed by us $^{32}$ and, more recently, confirmed to be important also for $\alpha$-syn modulation of other mitochondria related activities $^{33-35}$

Interestingly, $\alpha$-syn was found to localize both in vitro and in vivo at the outer membrane (OMM), the intermembrane space (IMS), the inner membrane or in the mitochondrial matrix depending on cell lines, species and culture conditions ${ }^{12,13,15,19,36-39}$. Whether the presence of $\alpha$-syn at specific sub-mitochondrial localization could be related to precise physiological and pathological circumstances remains elusive. Thus, we decided to investigate the sub-mitochondrial distribution of the WT and the PD-associated mutants of $\alpha$-syn. We also evaluated conditions that may favour $\alpha$-syn translocation into mitochondria in order to identify possible peculiar function for the specific sub-organelle targeted $\alpha$-syn.

We have applied a bimolecular fluorescence complementation (BiFC) approach ${ }^{40-42}$, previously developed $^{43}$ and recently improved ${ }^{44}$ by our group, to selectively monitor the sub-mitochondrial distribution of WT and PD-related $\alpha$-syn mutants A53T and A30P and test whether selected cellular stimuli could change their distribution.

This approach led us to identify WT and mutants $\alpha$-syn pools that under basal conditions constitutively reside at the OMM and in the IMS. No $\alpha$-syn molecules were instead detected in the mitochondrial matrix. Interestingly, a quantitative evaluation of the reconstituted fluorescent signal has permitted to establish that the presence of PD-related mutations A30P and A53T significantly enhanced the fraction of $\alpha$-syn found at the IMS. Moreover, we have found that oxidative stress induction, complex I inhibition and impairment of the endosome-lysosome acidification system selectively promoted the accumulation of WT but not of A30P and A53T mutant $\alpha$-syn within the IMS. Finally, we took advantage from the possibility to artificially targeting $\alpha$ syn to the mitochondrial matrix and to monitor whether its presence inside this sub-mitochondrial compartment could affect bioenergetic metabolism. Intriguingly, we have found that the presence of WT $\alpha$-syn in the mitochondrial matrix, but not that of the PD-related A30P and A53T mutants, was able to sustain mitochondrial ATP synthesis, underling a new possible physiological role for WT $\alpha$-syn and a new pathological mechanism for PDassociated mutations.

\section{Results}

\section{A split-GFP based tool to monitor sub-mitochondrial localization}

In order to follow the exact sub-mitochondrial localisation of $\alpha$-syn we applied the split-GFP based tool we had previously developed and described for other proteins of interest ${ }^{43,44}$. The $\mathrm{GFP}_{1-10}$ moiety lacking the S11 $\beta$-strand fused to the first 33 amino acids of the TOM20 N-terminal tail (OMM GFP $\left.{ }_{1-10}\right)$ or to the leader sequence of the inter membrane space protein LACTB (IMS GFP ${ }_{1-10}$ ) were employed to reveal the distribution of $\alpha$-syn at the cytosolic surface of the outer mitochondrial membrane and at the inter membrane space, respectively ${ }^{45,46}$. To reveal the presence of $\alpha$-syn in the mitochondrial matrix the $\mathrm{GFP}_{1-10}$ moiety was delivered to this sub-mitochondrial compartment by the fusion with the presequence of the subunit VIII of human cytochrome $\mathrm{c}$ oxidase (mt GFP $\left.{ }_{1-10}\right)$ as previously described ${ }^{43}$. As shown in Fig. 1a, these targeted GFP $_{1-10}$ chimerae will properly reconstitute their fluorescence only when a protein tagged with the lacking S11 $\beta$-strand is located at the same compartment ${ }^{43,44}$. Control experiments confirmed the proper targeting and the absence of fluorescent signal of the $\mathrm{mtGFP}_{1-10}$ moiety, Fig. S1, as well as their ability to undergo self-complementation, Fig. $\mathrm{S}^{43,44}$.

WT and mutant a-syn reside at the OMM and IMS but not in the mitochondrial matrix and their overexpression modulates mitochondrial ATP production

To investigate the sub-mitochondrial localization of WT $\alpha$-syn and its pathologic mutants, we co-transfected HeLa (Fig. 1b) and SHSY5Y neuroblastoma (Fig. 1c) cells with the above described $\mathrm{GFP}_{1-10}$ constructs and the untargeted WT, A53T and A30P $\alpha$-syn fused at their Cterminal with the S11 $\beta$-strand. The expression of $\alpha$-syn was verified using an anti $\alpha$-syn antibody, that has revealed a diffuse cytosolic pattern (Fig. 1b, c, in red). GFP complementation in cells overexpressing the OMM GFP ${ }_{1-}$ ${ }_{10}$ and the IMS GFP 1-10 $_{10}$ with the untargeted WT, A53T 





(see figure on previous page)

Fig. 1 a Cartoon of targeted split-GFP chimeras are able to complement at the OMM, within the IMS and in the mitochondrial matrix. Submitochondrial localization of wild type and mutant a-syn was analyzed in HeLa $\mathbf{b}$ and SHSY5Y $\mathbf{c}$ cells by the co-expression of the OMM, IMS and mitochondrial matrix targeted GFP $1-10$ non-fluorescent moiety and of the WT, A53T and A30P a-synS11. Confocal images were acquired at 488 and $594 \mathrm{~nm}$ excitation wavelength. Transfected cells were incubated with an anti a-syn primary antibody and stained with an Alexa 633 conjugated secondary antibody. Complementation of the GFP probes was revealed by fluorescent acquisition at $488 \mathrm{~nm}$ excitation wavelength. $\mathbf{d}$ Mitochondrial (**** $<0.0001$ vs. control cells) and e cytosolic ATP production upon histamine stimulation measured by mtLuc probe in HeLa cells overexpressing a-syn wt and mutants. At least 9 independent measurements for three independent transfections have been done for each construct. One-way ANOVA retrieved a $p$ value of 0.0001 . Dunnett's multiple comparison test retrieved a statistically significant difference between Ctrl and WT, A53T, and A30P $p<0.0001 \mathbf{d}$ while no statistically significant differences were found for panel e with one-way ANOVA. Average values shown as mean \% calculated from the counts per second (cps) with respect to control cells. Scale bar is $20 \mu \mathrm{m}$

and A30P $\alpha$-synS11 revealed that a pool of overexpressed $\alpha$-syn is localized both at the cytosolic surface of the outer mitochondrial membrane and in the intermembrane space (Fig. 1b, c, upper and middle panels). Interestingly, no fluorescence signal following excitation at $488 \mathrm{~nm}$ wavelength was detected in the mitochondrial matrix upon co-expression of the mtGFP ${ }_{1-10}$ and WT and mutant $\alpha$-synS11, indicating that the overexpression of $\alpha$ syn does not induce the accumulation of $\alpha$-syn in the mitochondrial matrix (Fig. 1b, c lower panels). To confirm the above mentioned results in a different dopaminergiclike cell model, we also performed the experiments in undifferentiated and differentiated BE(2)-M17 cell lines (Fig. 2 left and right, respectively and Fig. S3) and, as in the case of HeLa and SHSY5Y cells, we detected $\alpha$-syn at the OMM and the IMS but not in the mitochondrial matrix. The anti TOM20 immunostaining confirmed the mitochondrial specificity of GFP emission signals (Fig. $3 a-c)$.

To support our findings obtained with splitGFP method and to assess whether $\alpha$-syn variants differentially associate with the mitochondria, $\alpha$-syn abundance in cytosolic and mitochondrial fractions were obtained from HeLa cells transfected with WT, A30P, or A53T $\alpha$-syn expressing vectors was verified by Western Blot analysis (Fig. S4).

Quantification of mitochondrial $\alpha$-syn amount in respect to mitochondrial content, calculated as the normalized mitochondrial $\alpha$-syn/TOM20 ratio, showed no differences among the three different batches of transfected cells. Taken together, these results confirmed the presence of WT, A30P, or A53T $\alpha$-syn in mitochondrial fraction but did not revealed any differences in their quantitative distribution.

To assess whether $\alpha$-syn overexpression could affect mitochondrial bioenergetics, we analyzed mitochondrial and cytosolic ATP production upon cell stimulation with histamine, an inositol 1,4,5 tris-phosphate (InsP3)-producing agonist that mobilize $\mathrm{Ca}^{2+}$ from the endoplasmic reticulum. Mitochondrial (mtLUC) or cytosolic (cytLUC) recombinant luciferase probes and WT and mutant $\alpha$-syn were co-expressed in HeLa cells and ATP levels were monitored upon addition of luciferin, as previously described $^{47}$. Figure 1d shows the increment in light emission relative to the ATP production upon histamine stimulation, i.e., upon enhancement of energy requirement. Indeed, histamine stimulation by inducing transient mitochondrial $\mathrm{Ca}^{2+}$ concentration increases, stimulates Krebs cycle enzymes and enhances ATP production ${ }^{47}$. Mitochondrial ATP synthesis in cells overexpressing both the WT $\alpha$-syn as well as the pathologic $\alpha$-syn mutants is reduced of about $20 \%$ compared to control cells (whose levels are reported as 100\%), suggesting that $\alpha$-syn overexpression impaired ATP production independently from its PD-related mutations (mtLuc $100 \pm 0.77 n=14$; WT $\alpha$-syn 88.94 $\pm 1.02 n=14 ;$ A53T $\alpha$-syn $82.25 \pm 0.59 n=9$; A30P $\alpha$-syn $82,82 \pm 0.51 n=9$ ). Cytosolic ATP levels were instead essentially unaffected by the presence of overexpressed $\alpha$-syn (cytLuc $100 \pm 1.95 n=10$; WT $\alpha$-syn $95.66 \pm 1.43 n=11 ;$ A53T $\alpha$-syn $96.65 \pm 1.02 n=14$; A30P $\alpha$-syn $96.10 \pm 0.64 n=14$ ) (Fig. 1e).

\section{a-syn mitochondrial distribution is altered by the occurrence of pathogenic mutations and cellular stress conditions}

In order to investigate whether WT and mutant $\alpha$-syn possess different propensity to localize at the mitochondria compartment, we quantified GFP fluorescence in HeLa cells co-transfected with OMM and IMS GFP ${ }_{1-10}$ along with WT, A53T and A30P $\alpha$-synS11. From the images shown in Fig. 4a, it is evident that GFP fluorescent signal reconstituted by WT $\alpha$-synS11 at the OMM is much more intense with respect to that reconstituted upon the overexpression of the pathogenic mutants. The quantification of the corrected total cell fluorescence (CTCF) revealed that WT $\alpha$-synS11 has major propensity to localize at the OMM compared to mutant $\alpha$-synS11 (CTCF: WT $\alpha$-syn $1 \pm 0.08 n=32$; A53T $\alpha$-syn $0.59 \pm 0.05$ $n=34$; A30P $\alpha$-syn $0.71 \pm 0.06 n=29$ ) (Fig. 4b), whereas, on the opposite, a greater fluorescence signal is detectable at the IMS for the mutant constructs (Fig. 4c), indicating that the occurrence of pathogenic mutations is able to favor the translocation of the protein across the OMM in the IMS (CTCF: WT $\alpha$-syn $1 \pm 0.06 n=50$; A53T $\alpha$-syn 

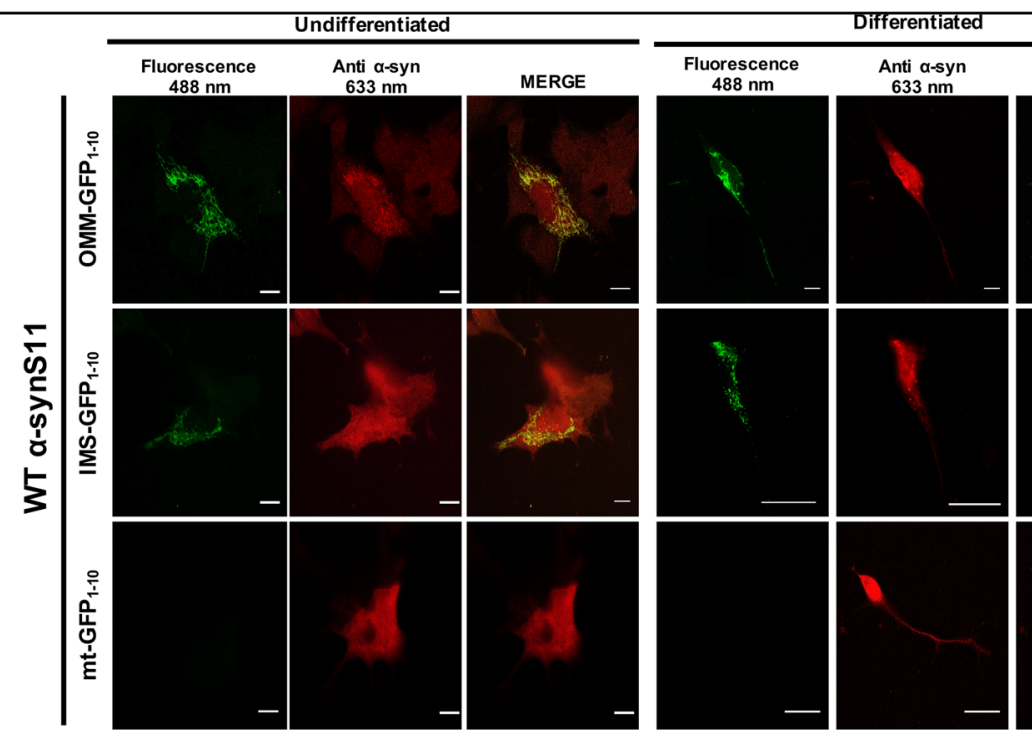

MERGE
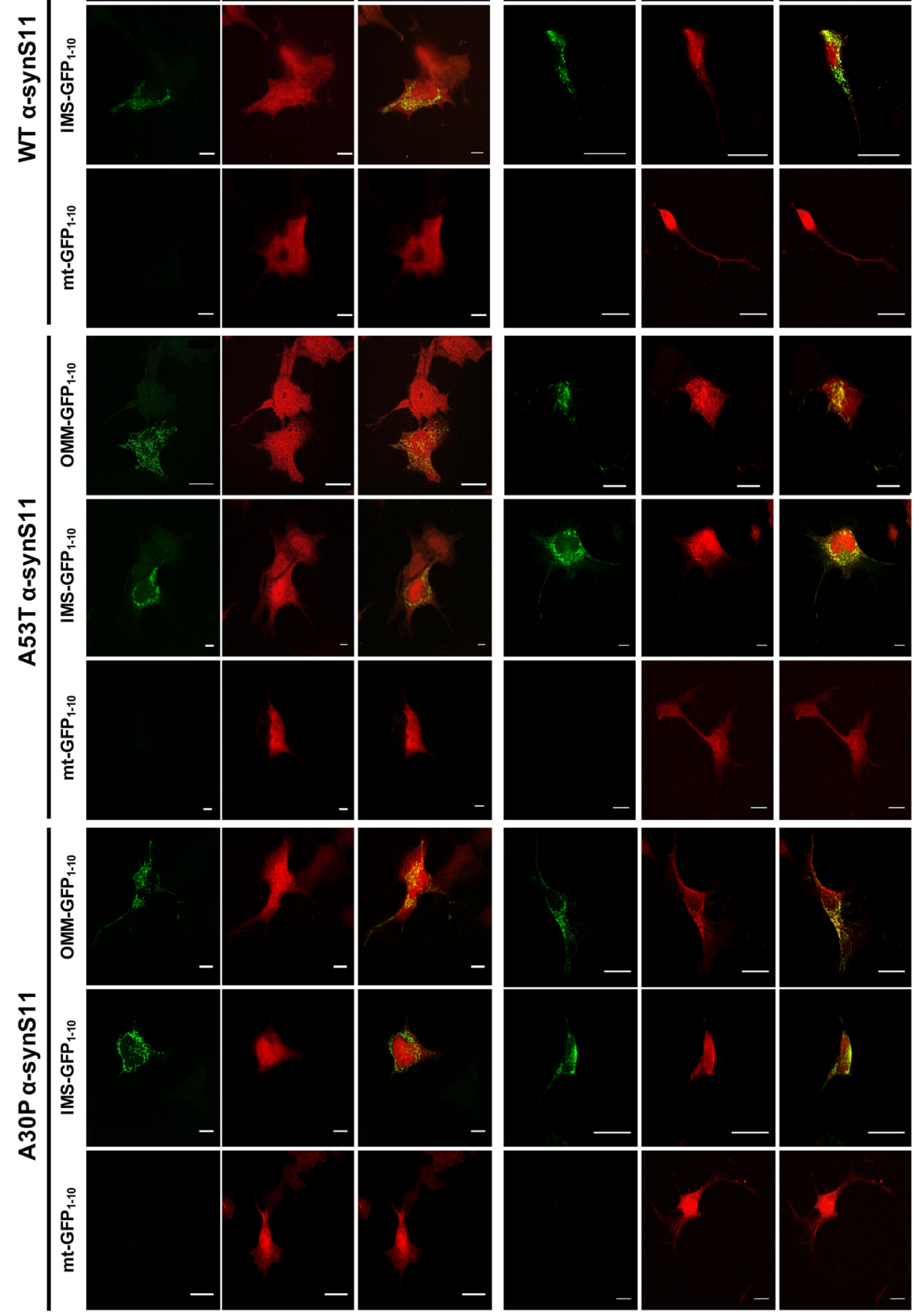

Fig. 2 Sub-mitochondrial localization of wild type and mutant $\mathbf{a}$-syn was analyzed in undifferentiated. $\mathbf{a}$ and differentiated $\mathbf{b} B E(2)-\mathrm{M} 17$ dopaminergic-like cells by the co-expression of the OMM, IMS and mitochondrial matrix targeted GFP ${ }_{1-10}$ non-fluorescent moiety and of the WT, A53T and A30P a-synS11. Confocal images were acquired at 488 and $594 \mathrm{~nm}$ excitation wavelength. Transfected cells were incubated with an anti asyn primary antibody and stained with an Alexa 633 conjugated secondary antibody. Complementation of the GFP probes was revealed by fluorescent acquisition at $488 \mathrm{~nm}$ excitation wavelength. Scale bar is $20 \mu \mathrm{m}$ 


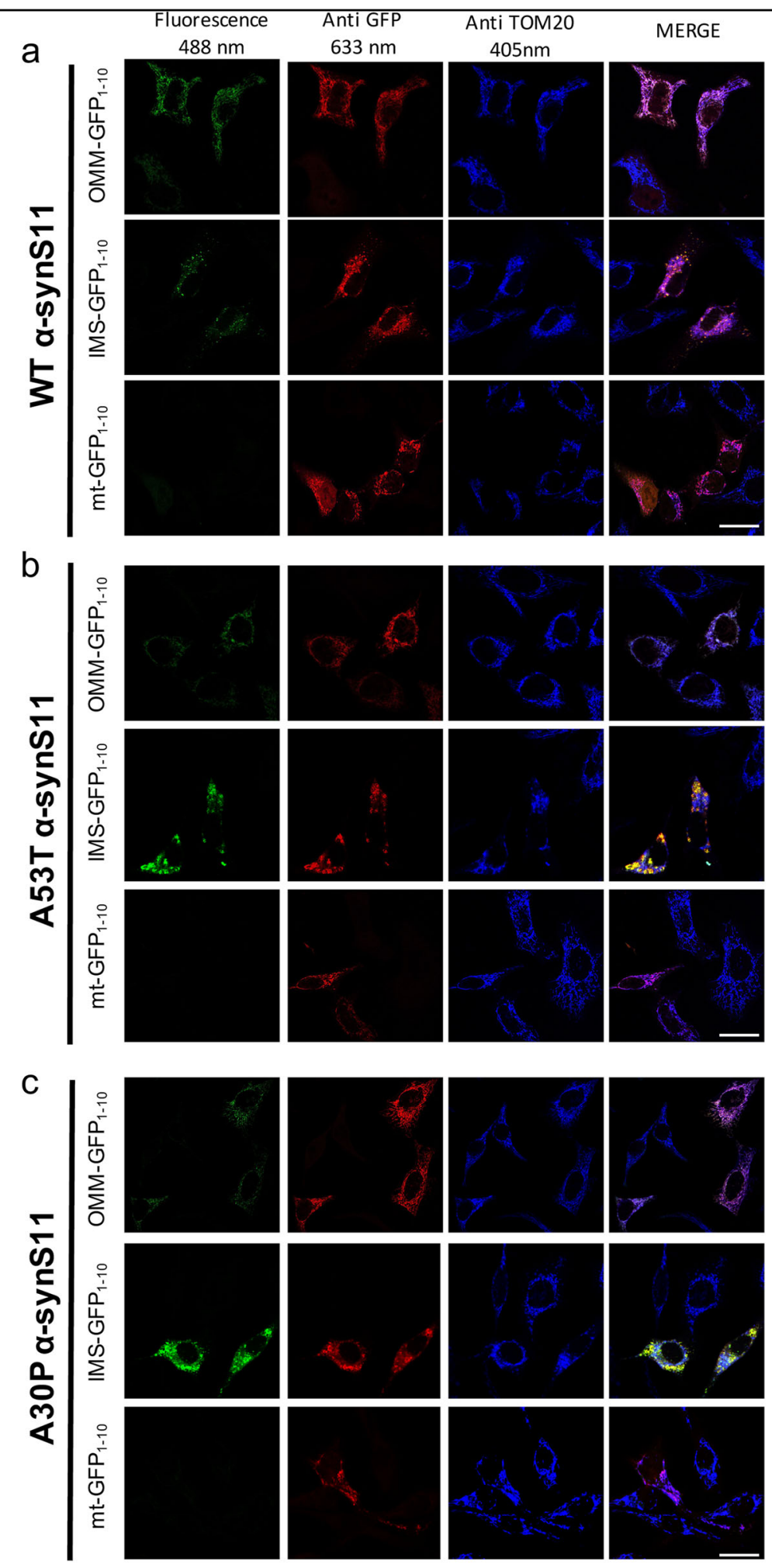

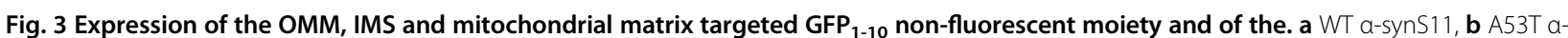
synS11, and c A30P a-synS11. Complementation of the GFP probes was revealed by fluorescent acquisition upon excitation at $488 \mathrm{~nm}$ wavelength. GFP was detected using a GFP primary antibody while mitochondria were stained using an anti TOM 20 antibody. Confocal images were acquired at 633 and $405 \mathrm{~nm}$ excitation wavelength. Cells were stained with anti GFP and anti TOM20 antibodies and observed at a confocal microscope at 405, 488 and $633 \mathrm{~nm}$ excitation wavelength. Scale bar is $20 \mu \mathrm{m}$ 


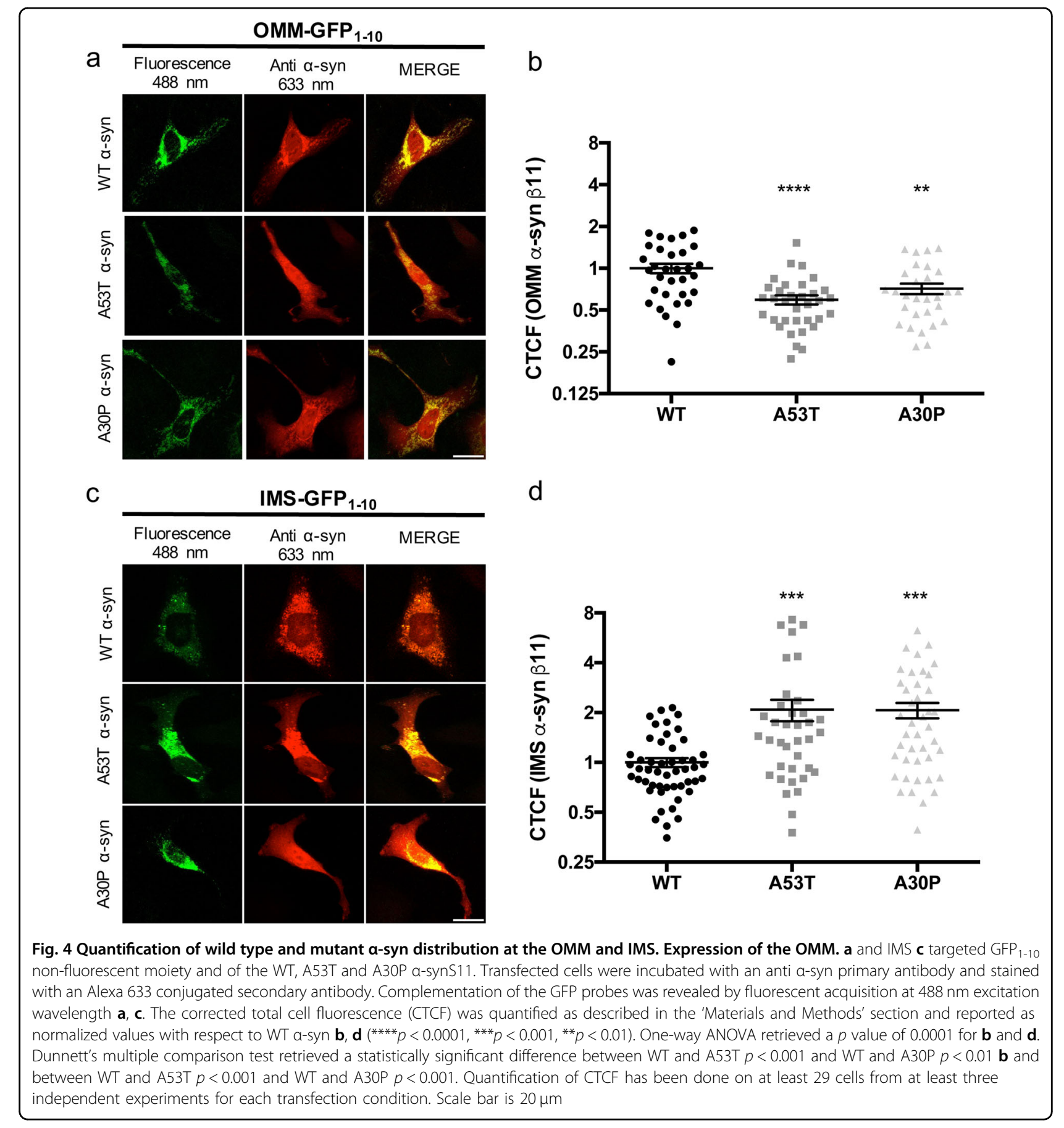

$2.08 \pm 0.31 n=37 ;$ A30P $\alpha$-syn $2.07 \pm 0.22 n=42$ ) (Fig. $4 d)$. To verify that the expression of $\alpha$-synS11 constructs was similar among the different batches of transfected cells and that the same correlation exist between the immunoreactive $\alpha$-synuclein signal and the fluorescence signal of reconstituted GFP we have quantified the red and the green fluorescence along the entire volume of the cells positive for reconstituted $\mathrm{GFP}_{1-10}$ and plotted them. As expected, a positive relationship is present for WT,
A53T and A30P $\alpha$-synS11 either at the OMM and at the IMS. However, a poor positive linear correlation is observed (Fig. S5) which is equivalent in all the batches of transfected cells (except for the A53T $\alpha$-synS11 at the OMM, see the $R^{2}$ values for comparison), suggesting that cell specific differences in the expression level of $\alpha$-synS11 do not affect the observed differences in fluorescence intensities among WT, A53T and A30P $\alpha$-synS11 within the same sub-mitochondrial compartment. 


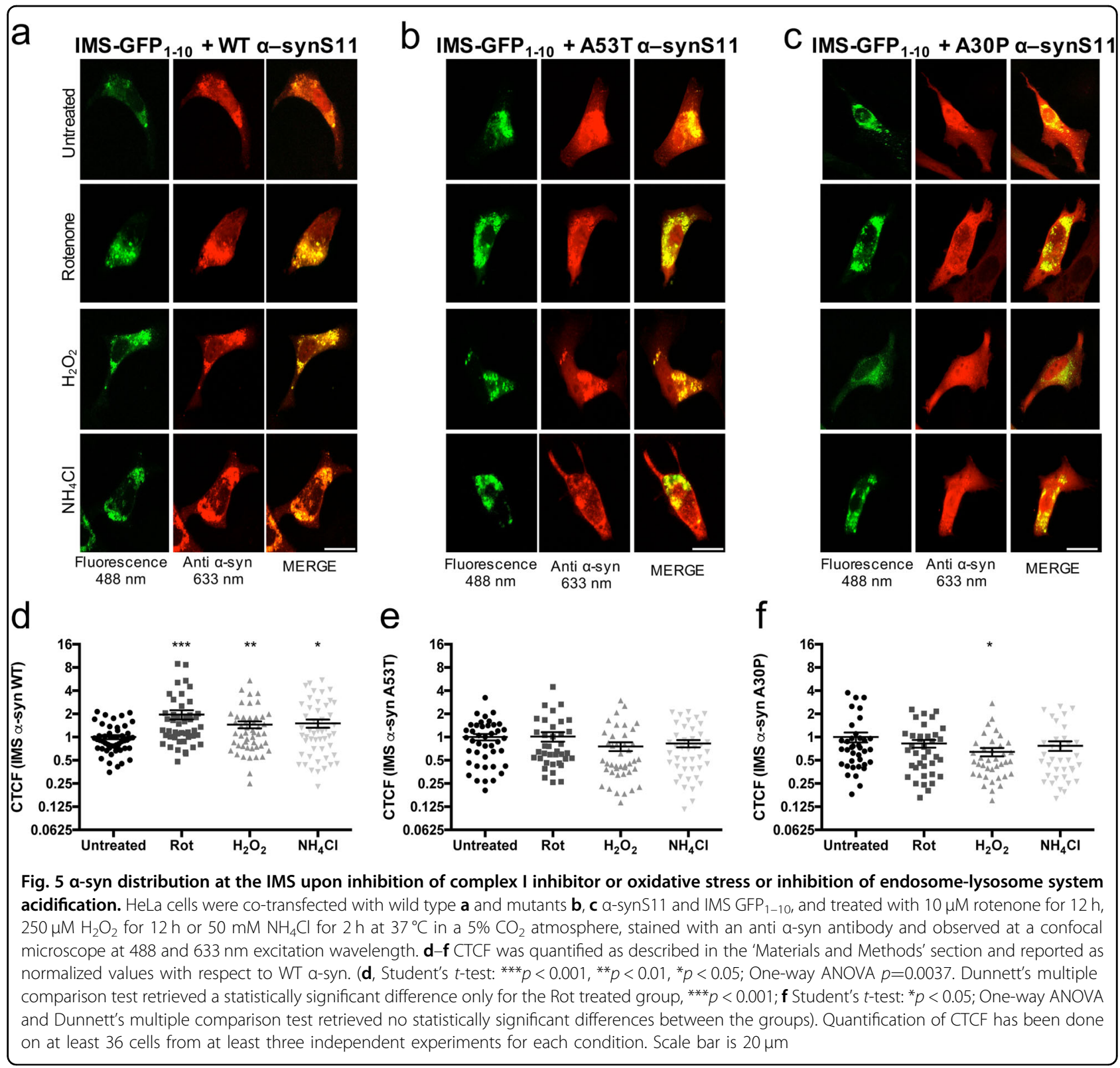

At the light of these results, we wanted to find specific cell conditions that may change $\alpha$-syn distribution at the OMM or the IMS. We decided to evaluate this aspect by monitoring $\alpha$-syn at the IMS. HeLa cells were transfected with IMS $\mathrm{GFP}_{1-10}$ and WT or mutant $\alpha$-synS11 and treated with $10 \mu \mathrm{M}$ rotenone for $12 \mathrm{~h}, 250 \mu \mathrm{M} \mathrm{H}_{2} \mathrm{O}_{2}$ for $12 \mathrm{~h}$, or $50 \mathrm{mM} \mathrm{NH} \mathrm{NH}_{4} \mathrm{Cl}$ for $2 \mathrm{~h}$ at $37^{\circ} \mathrm{C}$ in a $5 \% \mathrm{CO}_{2}$ atmosphere. As shown in Fig. 5a, d, there was a significant increase in WT $\alpha$-syn in the IMS in treated HeLa cells compared to control (WT $\alpha$-syn: control $1 \pm 0.06 n=50$; rotenone $1.96 \pm 0.27 n=48 ; \mathrm{H}_{2} \mathrm{O}_{2} 1.45 \pm 0.15 n=49$; $\left.\mathrm{NH}_{4} \mathrm{Cl} 1.51 \pm 0.18 n=54\right)$. Interestingly, upon the same stimuli, the IMS pool of $\alpha$-synS11 mutants did not changed (Fig. 5b, c), as better appreciable from the quantitative analysis shown in Fig. 5e, f (for A53T $\alpha$-syn: control $1 \pm 0.10 n=42$; rotenone $1.02 \pm 0.14 n=37 ; \mathrm{H}_{2} \mathrm{O}_{2}$ $0.76 \pm 0.10 n=42 ; \mathrm{NH}_{4} \mathrm{Cl} 0.82 \pm 0.09 n=42$ and for A30P $\alpha$-syn: control $1 \pm 0.15 n=37$; rotenone $0.82 \pm 0.10 n=$ 37; $\mathrm{H}_{2} \mathrm{O}_{2} 0.64 \pm 0.08 n=38 ; \mathrm{NH}_{4} \mathrm{Cl} 0.77 \pm 0.11 n=36$ ).

At this point we were interested to assess whether the same conditions that favoured WT $\alpha$-syn accumulation into IMS, may also lead to $\alpha$-syn translocation into the mitochondrial matrix. Thus, we performed similar experiments using the $\mathrm{mt} \mathrm{GFP}_{1-10}$ moiety: no fluorescence signal was detected for any of the $\alpha-\operatorname{synS} 11$ constructs upon cells incubation with rotenone, $\mathrm{H}_{2} \mathrm{O}_{2}$ or $\mathrm{NH}_{4} \mathrm{Cl}$ (data not shown), suggesting that these treatments, in our experimental conditions, do not induce WT 
and mutant $\alpha$-syn translocation into the mitochondrial matrix.

All together, these data suggest that the pathogenic mutations lead to $\alpha$-syn accumulation in the IMS and that pharmacological treatments that impair complex I activity or increase oxidative stress or inhibit the endosomelysosome system acidification mimic the same effect for WT $\alpha$-syn.

The artificial targeting of WT a-syn, but not of its pathogenic mutants, to the mitochondrial matrix sustains ATP synthesis in a Complex III-dependent manner

Although we were not able to detect the presence of $\alpha$ syn in the mitochondrial matrix (neither under basal nor under stress conditions), recent findings strongly supported the view that $\alpha$-syn can indeed reach the mitochondrial matrix and modulate ATP production and/or mitochondrial membrane potential ${ }^{33-35,38,48}$, indicating that in other cell types or under specific experimental conditions $\alpha$-syn could translocate in the mitochondrial matrix.

Indeed, it has been shown that exogenous monomeric WT $\alpha$-syn, but not its A30P mutant, is able to physically interact with the $\alpha$ subunit of the ATP synthase and to increase its activity in primary neuron/glia co-cultures from mice cerebral cortex ${ }^{38}$. Thus, we decided to directly investigate possible action on mitochondrial metabolism of $\alpha$-syn artificially targeted to the mitochondrial matrix. To this end, we generated a mitochondrial matrixtargeted $\alpha$-synS11 ( $\mathrm{mt} \alpha$-synS11) by adding the same targeting sequence that we have fused to the $\mathrm{GFP}_{1-10}$ fragment. mt $\alpha$-synS11 efficiently complemented $\mathrm{mtGFP}_{1-10}$, as revealed by the mitochondrially localized green fluorescent signal observed following excitation at $488 \mathrm{~nm}$ wavelength (Fig. 6a). To evaluate its possible impact on mitochondria function, mitochondrial ATP production upon cells stimulation with histamine was measured in parallel both in cells overexpressing $\mathrm{mt} \alpha$-synS11 or untargeted $\alpha$-synS11. As shown in Fig. 6b, while the overexpression of untargeted $\alpha$-syn reduced mitochondrial ATP synthesis (as already shown in Fig. 1e), the mt $\alpha$-synS11 was able to enhance ATP production (Mean values (\% cps): mt Luc $100 \pm 1.49 n=17$; mt $\alpha$-syn $106.29 \pm 1.28 n=19 ; \alpha$-syn $94.27 \pm 0.50 n=11$ ). Interestingly, $\mathrm{mt} \alpha$-synS11 still exerted this effect in the presence of complex I inhibitor rotenone (Mean values (\% cps): mt Luc $94.45 \pm 1.29 n=13$; mt $\alpha$-syn $100.88 \pm 1.83$ $n=10 ; \alpha$-syn $88.48 \pm 0.39 n=11$ ) (Fig. 6c), while the ability to promote ATP synthesis was lost in the presence of the complex III inhibitor antimycin, (Mean values (\% cps): mt Luc $88.20 \pm 0.86 n=12$; mt $\alpha$-syn $87.24 \pm 0.83$ $n=13$; $\alpha$-syn $86.66 \pm 0.58 n=11$ ) (Fig. $5 \mathrm{~d}$ ). Of notice, pathogenic mutants of $\alpha$-syn artificially targeted to the mitochondrial matrix are not able to increase mitochondrial ATP synthesis upon cell stimulation, (Mean values (cps): mt Luc $100 \pm 0.63 n=17$; mt A53T $\alpha$-syn $99.20 \pm$ $1.08 n=18$; mt A30P $\alpha$-syn $101.13 \pm 0.90 n=15$ ) (Fig. 6e).

To check whether the observed increases in ATP production could be related to possible effects of $\mathrm{mt} \alpha$-synS11 on mitochondrial $\mathrm{Ca}^{2+}$ uptake, as previously shown for untargeted cytosolic $\alpha$-syn ${ }^{32}$, mitochondrial $\mathrm{Ca}^{2+}$ measurements were performed using mitochondrially targeted photoprotein aequorin ${ }^{49,50}$. No alterations in mitochondrial $\mathrm{Ca}^{2+}$ levels were registered upon histamine stimulation in cells overexpressing the wt or the mutated mitochondrial matrix targeted $\alpha$-syn constructs, indicating that the sustained ATP levels are not driven by an increase in mitochondrial $\mathrm{Ca}^{2+}$ transients that could stimulate the Krebs cycle (Peak values $(\mu \mathrm{M})$ : mtAEQ $124.19 \pm 7.40 n=12$; mt WT $\alpha$-syn $125.18 \pm 5.34 n=14$; mt A53T $\alpha$-syn $130.98 \pm 6.35 n=13$; mt A30P $\alpha$-syn $134.57 \pm 4.77 n=13$ ) (Fig. 6f). These findings suggest that WT $\alpha$-syn, resident in the mitochondria matrix, could play a direct role on ATP production by the modulation of the respiratory chain (possibly through complex III activity) and that the presence of pathogenic mutations compromises this function.

\section{VDAC 1-3 are not responsible for a-syn translocation inside mitochondria}

The evidence that a portion of $\alpha$-syn resides at the IMS, requires the direct translocation of the protein from the cytosol across the outer mitochondrial membrane. Recent in vitro experiments using the Voltage Anion Channel (VDAC) reconstituted into planar lipid membranes suggested that $\alpha$-syn is able to interact with/translocate through the VDAC1 to reach the IMS ${ }^{51,52}$. To verify the possibility that VDAC could represent a docking site for $\alpha$-syn entry in IMS in living cells, we transfected mouse embryonic fibroblasts (MEF) WT and MEF VDAC 1-3 KO with IMS GFP $1-10$ and WT or mutant $\alpha$-synS11: we could expect that the ablation of the channel could prevent $\alpha$-syn translocation across the OMM. Surprisingly, we have found that VDAC 1-3 absence does not alter the ability of $\alpha$-syn (WT and mutants) to translocate to the IMS, as revealed by the specific complementation of the fluorescent probe and the resulting green fluorescence emission (Fig. 7). These data clearly suggest that VDAC 1-3 are not essential for $\alpha$-syn translocation inside mitochondria in intact cells. Whether this indicate that VDAC 1-3 proteins are not the only channels implicated in $\alpha$-syn translocation or that $\alpha$-syn takes completely different routes to reach the IMS (i.e., by TOM40 as previously suggested ${ }^{14}$ ) remains to be further elucidated.

\section{In vivo localization of a-syn at the OMM and the IMS, but not the mitochondrial matrix}

The above mentioned experiments suggested the existence of a mitochondrial pool of $\alpha$-syn at the OMM and at 

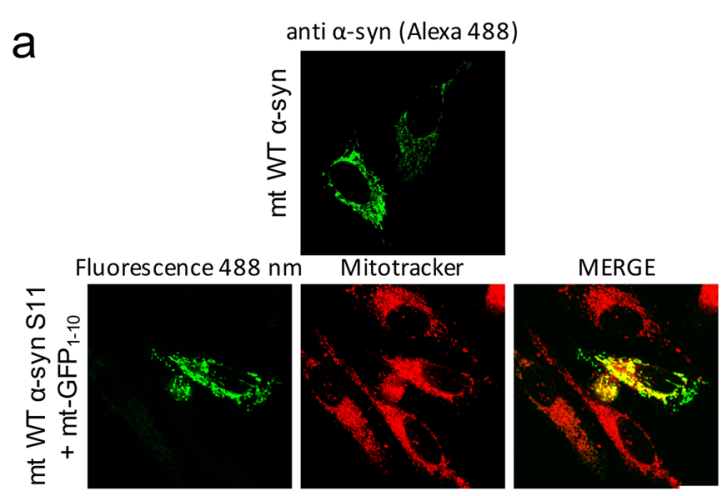

C
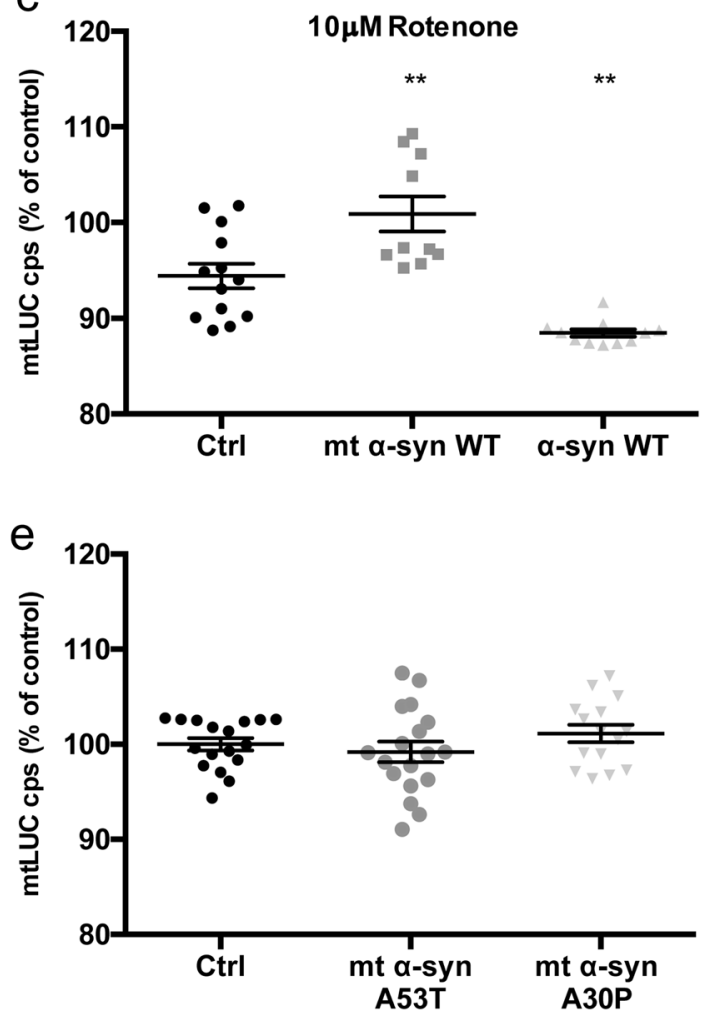

b

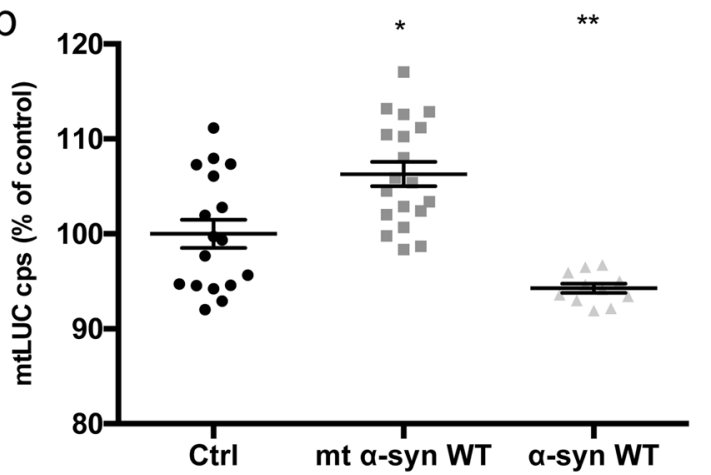

d

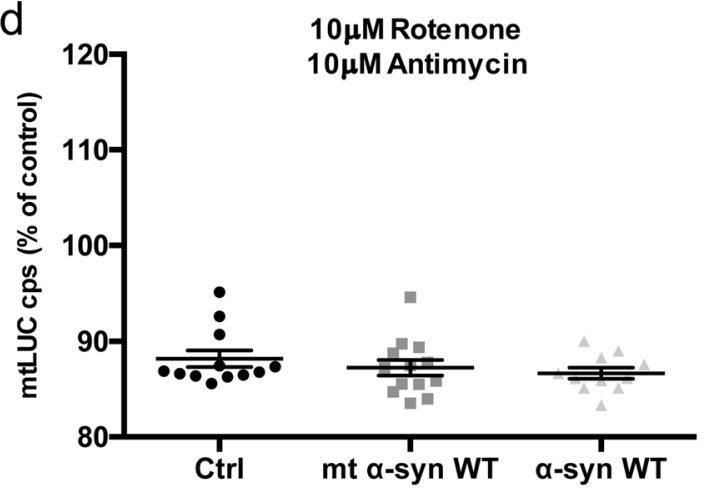

f

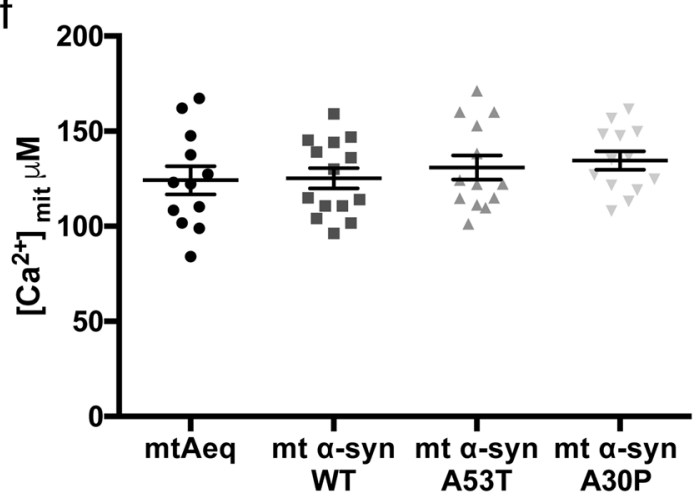

Fig. 6 WT and mutant a-syn targeting to the mitochondrial matrix differently affects mitochondrial ATP levels. a Complementation of the mitochondrial matrix targeted GFP $1-10$ non-fluorescent moiety upon co-expression of the targeted mt WT a-synS11. The mitochondrial localization was verified by mitotracker staining. Confocal images were acquired at 488 and $594 \mathrm{~nm}$ excitation wavelength. b, c, d Histograms showing mitochondrial ATP production upon histamine stimulation measured by mtLuc probe in HeLa cells overexpressing untargeted or mitochondrial matrix targeted a-syn in HeLa cells untreated $\mathbf{b}$ or treated with $10 \mu \mathrm{M}$ rotenone $\mathbf{c}$ or $\mathbf{d} 10 \mu \mathrm{M}$ rotenone $+10 \mu \mathrm{M}$ antimycin for $12 \mathrm{~h}$ at $37^{\circ} \mathrm{C}$ in a $5 \%$ $\mathrm{CO}_{2}$ atmosphere. e Histograms showing mitochondrial ATP production upon histamine stimulation measured by mtLuc probe in HeLa cells overexpressing mitochondrial matrix targeted $\mathrm{mt} \mathrm{WT}$, mt A53T and mt A30P a-syn. Average values are shown as mean \% calculated from the counts per second (cps) with respect to control cells. $\mathbf{f}$ Mitochondrial $\mathrm{Ca}^{2+}$ transients upon stimulation with $100 \mu \mathrm{M}$ histamine were measured in HeLa cells by co-transfecting mtAEQ and empty vector, or mt WT, mt A53T and mt A30P a-syn. Bars represent mean $\mathrm{Ca}^{2+}$ peak values upon histamine stimulation. Data were collected from at least 10 coverslips/conditions from three independent experiments. (One-way ANOVA coupled with Dunnett's multiple comparison test retrieved a statistically significant difference between the groups: $\left.{ }^{* *} p<0.01,{ }^{*} p<0.05\right)$. At least 10 independent measurements for three independent transfections have been done for each construct. Scale bar is $20 \mu \mathrm{m}$ 


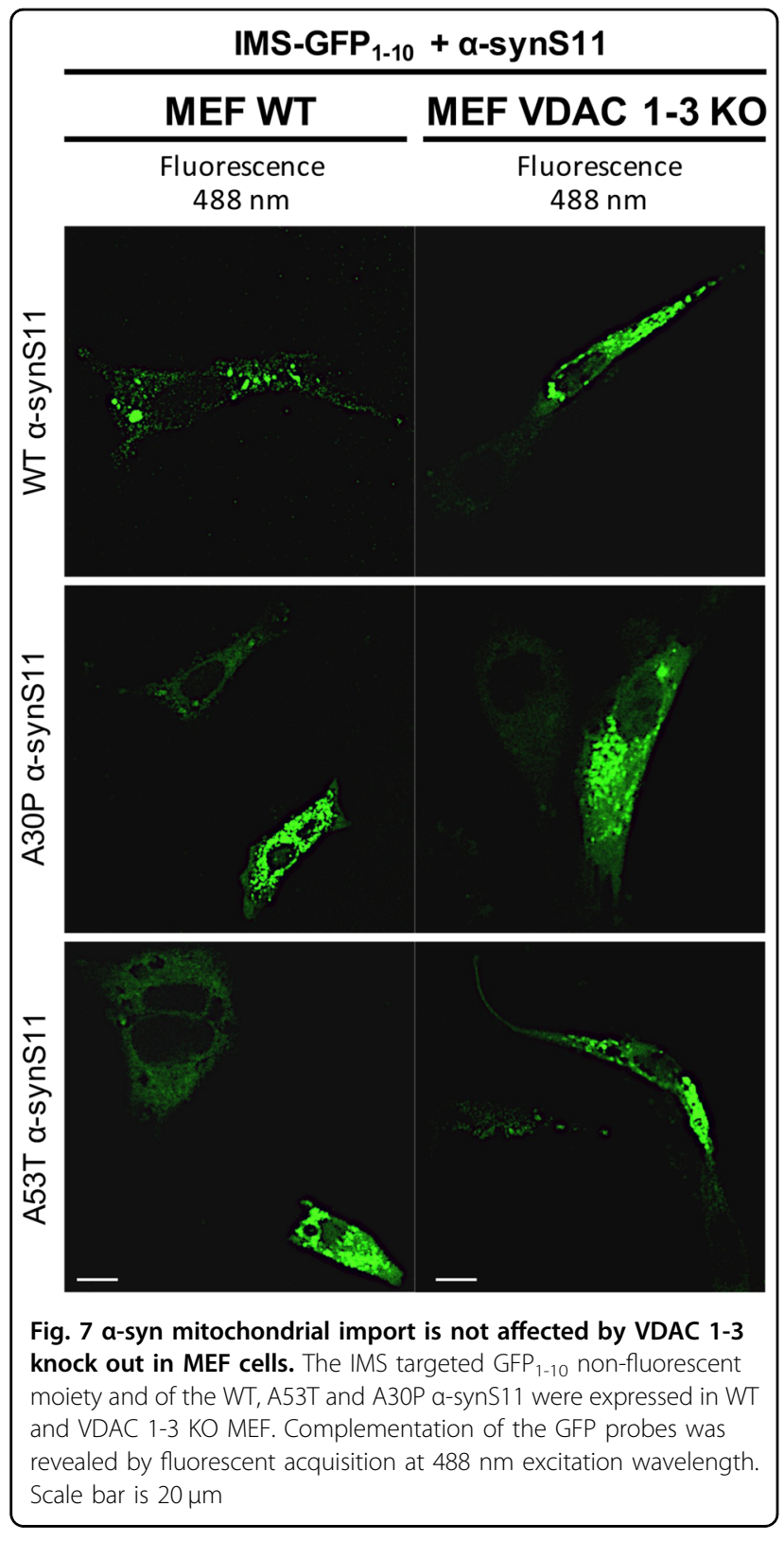

the IMS while, under basal conditions we could never detect it within the mitochondrial matrix. To further validate these findings in a more complex system, we decided to test for the first time the possibility to follow the translocation of a protein of interest within mitochondrial sub compartments with our splitGFP system in the living vertebrate Danio Rerio. To this aim, fertilized oocytes at the stage of 1 cell have been microinjected with the plasmids encoding for $\alpha$-synS11 (either WT, A53T or A30P) together with the OMM GFP ${ }_{1-10}$, the IMS GFP I-10 $_{10}$ or the $\mathrm{mtGFP}_{1-10}$ at the final concentration of $100 \mathrm{ng} / \mu \mathrm{l}$. Under these conditions, a mosaic expression is expected to take place. Injected embryos at $1 \mathrm{dpf}$ have been dechorionated, anesthetized and mounted in low melting agarose. Confocal z-stacks were acquired in vivo and, as shown in Fig. 8, a clear and strong signal can be detected with the OMM and the IMS GFP1-10 probes co-injected with either WT, A53T or A30P $\alpha$-synS11, suggesting that a fraction of $\alpha$-syn is indeed present at the OMM as well as the IMS in living zebrafish. On the other side, no mitochondrial signal could be detected by using the matrix targeted $\mathrm{GFP}_{1-10}$ supporting the idea that, under basal conditions, $\alpha$-syn does not reach the mitochondrial matrix. These results have confirmed the findings we have obtained in HeLa and dopaminergic cells and, intriguingly, have also demonstrated that our splitGFP assay is suitable for in vivo settings.

\section{Discussion}

Mitochondrial dysfunctions and $\alpha$-syn accumulation into Lewy bodies are both considered as key events in the progressive loss of dopaminergic neurons leading to PD manifestation. Although the precise role of $\alpha$-syn in the neurodegenerative process is largely unknown, several lines of evidence have highlighted its possible involvement in the regulation of mitochondrial functions. For these reasons, numerous studies have focused their attention on $\alpha$-syn contribution to the control of mitochondrial activities $^{53,54}$. Nevertheless, whether mitochondrial dysfunctions represent a secondary event in $\alpha$-syn-induced alterations or are directly triggered by $\alpha$-syn at the mitochondrial level is still unclear. Moreover, the absence of techniques that allow to specifically monitor the protein's distribution inside organelles, further intricate the road to a complete understanding of $\alpha$-syn physio/ pathology inside mitochondria. Here, we employed a split-GFP based bimolecular fluorescence complementation (BiFC) tool ${ }^{40,42}$ developed by our group to selectively monitor DJ-1 sub-mitochondrial distribution ${ }^{43}$ and further improved with a novel non fluorescent GFP $_{1-10}$ moiety targeted to the IMS ${ }^{55}$ to selectively follow proteins translocation inside the inter membrane space. Our analyses revealed that a fraction of WT, A30P and A53T $\alpha$ syn is localized at mitochondria both at the OMM and in the IMS, and that the overexpression of $\alpha$-syn resulted in a decrease in mitochondrial ATP production upon cell stimulation, as reported by others ${ }^{19}$. This result was partially unexpected considering that we had previously shown that $\alpha$-syn overexpression was able to enhance ERmitochondria $\mathrm{Ca}^{2+}$ transfer ${ }^{32}$, thus leading to the possibility that increased mitochondrial $\mathrm{Ca}^{2+}$ transients could augment ATP production. But it could be rationalized assuming that increased ER-mitochondria tethering may represent a compensatory response to cope with reduced mitochondrial ATP production in the presence of increased amount of $\alpha$-syn and that in the absence of this compensatory response the deficit in ATP synthesis could be even greater. Interestingly, while the WT protein is 


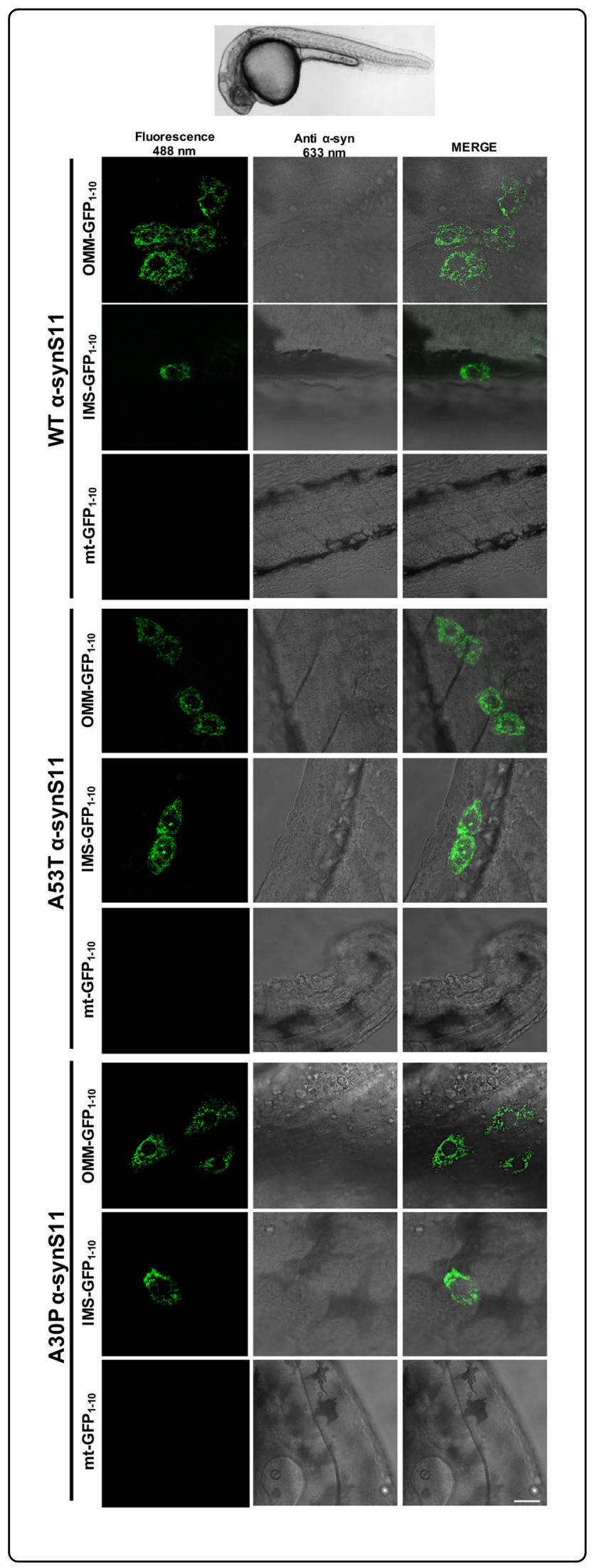

Fig. 8 Live imaging of SPLIT GFP reconstitution in $1 \mathrm{dpf}$ zebrafish embryos. Wild type zebrafish embryos at 1-cell stage were injected with a plasmid expressing human WT or A53T and A30P mutants asynS11 together with a plasmid expressing OMM-GFP ${ }_{1-10}$, IMS$\mathrm{GFP}_{1-10}$ or mt-GFP ${ }_{1-10}$. For the injections, the concentration of each plasmid was $50 \mathrm{ng} / \mathrm{ul}$. After 1 day, images were collected. Each picture is the merge of several planes. Scale bar is $20 \mu \mathrm{m}$

prevalently localized at the OMM, the pathologic mutants show a major IMS distribution, in agreement with previous results showing a lower degree of localization of both mutant $\alpha$-syn species to the endoplasmic reticulummitochondria interface compare with WT and a concomitantly higher degree of localization to the pure mitochondrial fraction ${ }^{18}$. Interestingly enough, we were able for the first time to test this system in a living vertebrate, i.e., the zebrafish Danio Rerio and confirm the presence of $\alpha$-syn at the OMM and at the IMS, as well as its absence in the mitochondrial matrix under basal conditions. Our data indicate that conditions of cellular stresses promote the translocation of the WT protein to IMS, but not that of the mutant species, that are more abundant per se in this compartment, suggesting the possibility that the recruitment of $\alpha$-syn from the OMM surface inside mitochondria, i.e., in the IMS and, possibly into the matrix where it enhances ATP production, could represent an initial step to counteract cell impairment and sustain bioenergetics. However, whenever $\alpha$-syn accumulation become excessive, $\alpha$-syn may fail to be imported in the mitochondrial matrix and stacked at the IMS where could be responsible for mitochondrial fragmentation, a mechanism of action previously suggested ${ }^{29,30}$ and recently confirmed ${ }^{56}$ to occur. Whether the different behavior of WT and mutant $\alpha$-syn reflects possible role of $\alpha$-syn inside mitochondria, i.e., in controlling mitochondrial dynamics ${ }^{54}$ or ATP production ${ }^{38}$, or is driven by a specific import of misfolded/aggregation prone proteins into mitochondria for their degradations, as recently suggested $^{57}$, deserves further investigation. Interestingly, Pozo Devoto and coworkers have recently shown that $\alpha$ syn plays a direct physiological role in mitochondrial transport and morphology and that due to the different affinity for membrane lipids the association of WT and A53T or A30P $\alpha$-syn with the mitochondria was different, thus suggesting that their effects on mitochondria are also dose-dependent ${ }^{56}$.

Since recent evidence have shown that in primary neuron/glia co-cultures exogenous monomeric $\alpha$-syn is able to physically interact with the $\alpha$ subunit of the ATP synthase $^{38}$, indicating a distinctive localization of the protein inside the mitochondrial matrix, we decided to evaluate phenotypes associated with this peculiar $\alpha$-syn distribution by artificial targeting $\alpha$-syn protein to the mitochondrial matrix. Interestingly, and in agreement 
with previous studies ${ }^{38}$, mitochondrial matrix-targeted WT $\alpha$-syn is able to sustain mitochondrial ATP synthesis, while mutant species targeted to the mitochondrial matrix do not promote mitochondrial ATP production. We have found that this action is dependent on complex III activity, since it is prevented by the incubation with the complex III inhibitor antimycin. In this context, one may speculate that, in neurons, a pool of $\alpha$-syn exerts a physiological role inside the mitochondrial matrix where it is able to increase ATP synthase activity ensuring mitochondrial health and synaptic functions and that another pool of $\alpha$-syn may be recruited to this site upon stress condition to further sustain ATP production through the modulation of complex III activity. The occurrence of mutations may lead to a loss of function that causes energy depletion and neuronal cell toxicity, thus initiating the degenerative process in PD.

\section{Materials and methods DNA constructs}

The full length $\alpha$-syn WT, A53T and A30P - $\beta 11$ construct have been generated by PCR using the following primers: $\alpha$-syn-S11 (HindIII) For 5' - GTTCAAGCTTA TGGATGTATTCATGAAAGG -3'; $\alpha$-syn-S11 (XhoI) Rev. 5'-ACTTCTCACTCGAGTTATGTGATGCCGGC GGCGTTCACGTA CTCGTGCAGCACCATGTGGTCC CGGCTGCCGCCGCCGCTGCCGCCGTCGCCGGCTT CAGGTTCGTAGTCTTG-3' The DNA constructs encoding for the human $\alpha$-syn WT, A30P and A53T used as a template are a kind gift of Prof. Alessandro Negro (Department of Biomedical Sciences, University of Padova). The C-terminus $\boldsymbol{\beta} 11$-tagged Cytochrome-c was produced by DNA synthesis (Thermo Scientific). Untargeted, mitochondrial matrix- and OMM-targeted humanized GFP 1-10 expressing vectors were generated by PCR amplification from the GPI-GFP1-10 template using forward primers containing the mitochondrial matrix presequence of the subunit VIII of cytochrome c oxidase and the Nterminal 33 amino acids sequence of TOM20 protein ${ }^{43}$.

The GFP $_{1-10}$ targeted to the intermembrane space (IMS) has been created by genetic fusion to the leader sequence of the IMS protein LACTB $^{44}$ and created by DNA synthesis (Thermo Scientific).

\section{Cell cultures and transfection}

HeLa, SHSY5Y cells and VDAC1/3 ${ }^{-1-}$ MEFs were grown in DMEM high glucose (Euroclone) containing $10 \%$ fetal bovine serum (FBS, Gibco), supplemented with $100 \mathrm{U} / \mathrm{ml}$ penicillin (Euroclone) and $100 \mu \mathrm{g} / \mathrm{ml}$ streptomycin (Euroclone), in a humidified atmosphere containing $5 \% \mathrm{CO}_{2}$. Undifferentiated $\mathrm{BE}(2)-\mathrm{M} 17$ cells were maintained in a 1:1 mixture of Ham's F12 and Dulbecco's Modified Eagle's Medium (Gibco) supplemented with $10 \%$ fetal bovine serum and grown in a humidified incubator at $37^{\circ} \mathrm{C}$ in the presence of $5 \% \mathrm{CO}_{2}$. The cell medium was replaced every 2 days, and the cells were subcultured once confluence was reached. In all of the experiments, the cells were used at early passages (P1-5 after purchase). Differences in morphology between proliferative and differentiated cells were evaluated by phase contrast light microscopy.

Cells were seeded onto 13 or $24 \mathrm{~mm}$ diameter glass coverslips and transfection was performed at $60-80 \%$ confluence using Lipofectamine TM 2000 Transfection Reagent (Life Technologies) for SHSY5Y, BE(2)-M17 and MEFs and the calcium-phosphate procedure for HeLa cells. To analyze the presence of $\alpha$-syn in the mitochondrial sub-compartments after differentiation, BE(2)-M17 cells were seeded onto coverslips pre-coated with poly-Dlysine $^{58}$. After $24 \mathrm{~h}$, differentiation was induced by the addition of retinoic acid (RA) at concentrations of $5 \mu \mathrm{M}$. Fresh media containing RA was provided every 2 day and 7 days later the cells were transfected with the vectors containing the coding sequence for targeted $\mathrm{GFP}_{1-10}$ chimerae and WT, A53T or A30P $\alpha$-syn. After $48 \mathrm{~h}$ the samples were fixed and processed for immunocytochemistry. For $\mathrm{Ca}^{2+}$ measurement cells were cotransfected with aequorin construct targeted to the mitochondrial matrix ${ }^{49}$. Cells were generally analyzed 24-48 $\mathrm{h}$ after transfection.

\section{Immunocytochemistry analysis}

After $48 \mathrm{~h}$ of transfection, cells plated on $13 \mathrm{~mm}$ glass coverslips were washed twice with phosphate-buffered saline (PBS: $140 \mathrm{mM} \mathrm{NaCl}, 2 \mathrm{mM} \mathrm{KCl}, 1.5 \mathrm{mM} \mathrm{KH}_{2} \mathrm{PO}_{4}$, $8 \mathrm{mM} \mathrm{Na}_{2} \mathrm{HPO}_{4} \mathrm{pH} 7.4$ ) and fixed for 20 min with $3.7 \%$ formaldehyde in PBS. Cells permeabilization was performed by 20 min' incubation with $0.1 \%$ Triton X-100 in PBS, followed by 30 min' wash with $1 \%$ gelatin (type IV, from calf skin, Sigma) in PBS. The coverslips were then incubated for $90 \mathrm{~min}$ at $37^{\circ} \mathrm{C}$ in a wet chamber with the specific primary antibody diluted in PBS: anti-GFP (Santa Cruz, sc-9996) anti-alpha synuclein (Santa Cruz, sc12767), anti-TOM20 (Santa Cruz, sc-11415). Staining was revealed by the incubation with specific AlexaFluor 405, 488 or 633 secondary antibodies, 1:50 (Life technologies) for $45 \mathrm{~min}$ at room temperature. Fluorescence was detected with a Leica SP5 confocal microscope and analyzed by ImageJ software.

\section{Quantification of BiFC at the OMM and IMS}

To quantify fluorescence signals, the corrected total cell fluorescence (CTCF) was calculated according to the protocol described in ${ }^{59}$. Briefly, a complete $z$-stack of cells showing a clear fluorescence signal was acquired using a Leica SP5 confocal microscope. The total corrected cell fluorescence (CTCF) was calculated by selecting the cell using the freehand selection of Fiji in the drawing/selection 
polygon tool and the area, the integrated density and the mean grey value are measured while the remaining signal coming from outside the cell was removed. Area, integrated density and mean grey value were then measured within the cells and three selected non-fluorescent area in the image were chosen as background. At least three additional selections from a non-fluorescent region next to the cell of interest were acquired and considered as background. The CTCF was calculated as follow: integrated density - (area of selected cell $\times$ mean fluorescence of background readings). The calculated CTCF was then normalised against the CTCF values of wt $\alpha$-syn-expressing cells. The results are shown as fold change increase/decrease over wt $\alpha$-syn expressing cells CTCF levels.

\section{Luciferase assay}

Luciferase luminescence was measured, as previously described ${ }^{47}$. HeLa cells co-transfected with a mitochondrial luciferase chimera $\left(\mathrm{mtLuc}^{47}\right)$ were perfused at $37^{\circ} \mathrm{C}$ with KRB (125 mM NaCl, $5 \mathrm{mM} \mathrm{KCl,} 1 \mathrm{mM} \mathrm{Na}{ }_{3} \mathrm{PO}_{4}$, $1 \mathrm{mM} \mathrm{MgSO}_{4}, 20 \mathrm{mM}$ HEPES, $\mathrm{pH} 7.4,37^{\circ} \mathrm{C}$ ) containing $1 \mathrm{mM} \mathrm{CaCl}_{2}, 5.5 \mathrm{mM}$ glucose and $20 \mu \mathrm{M}$ luciferin. In total $100 \mu \mathrm{M}$ histamine was added to the perfusion medium to induce mitochondrial ATP synthesis ${ }^{47}$. For each measurement, the light emission (cps, counts per second) after histamine application was normalized on cps emitted after luciferin addition. Where indicated, $10 \mu \mathrm{M}$ rotenone and $10 \mu \mathrm{M}$ antimycin were incubated for $12 \mathrm{~h}$ at $37^{\circ} \mathrm{C}$ in a $5 \%$ $\mathrm{CO}_{2}$ atmosphere.

\section{Aequorin measurements}

After $48 \mathrm{~h}$ of transfection mitochondrial low affinity aequorin (mtAEQ) was reconstituted by incubating cells for $1.5 \mathrm{~h}$ with $5 \mu \mathrm{M}$ wt coelenterazine (Santacruz) in DMEM supplemented with $1 \%$ fetal bovine serum at $37^{\circ} \mathrm{C}$ in a $5 \%$ $\mathrm{CO}_{2}$ atmosphere. After reconstitution, cells were transferred to the chamber of a purpose-built luminometer, and $\mathrm{Ca}^{2+}$ measurements were started in Krebs-Ringer modified buffer (KRB, $125 \mathrm{mM} \mathrm{NaCl}, 5 \mathrm{mM} \mathrm{KCl}, 1 \mathrm{mM} \mathrm{Na} \mathrm{PO}_{4}, 1 \mathrm{mM}$ $\mathrm{MgSO}_{4}, 5.5 \mathrm{mM}$ glucose, $20 \mathrm{mM}$ HEPES, $\mathrm{pH} 7.4,37^{\circ} \mathrm{C}$ ) medium supplemented with $1 \mathrm{mM} \mathrm{CaCl}$ by stimulating HeLa cells with $100 \mu \mathrm{M}$ histamine. The experiments were terminated by cell permeabilization with $100 \mu \mathrm{M}$ digitonin in a hypotonic $\mathrm{Ca}^{2+}$-rich solution $\left(10 \mathrm{mM} \mathrm{CaCl}_{2}\right.$ in $\left.\mathrm{H}_{2} \mathrm{O}\right)$ to discharge the remaining unused aequorin pool. The light signal was collected and calibrated off-line into $\mathrm{Ca}^{2+}$ concentration values using a computer algorithm based on the $\mathrm{Ca}^{2+}$ response curve of mitochondrial aequorin, as previously described ${ }^{60}$.

\section{Live imaging of asyn sub mitochondrial localization in Zebrafish}

The human WT, A53T or A30P mutant $\alpha$ synS ${ }_{11}$ plasmids were injected into 1 cell stage WT eggs together with a plasmid expressing OMM-GFP ${ }_{1-10}$, IMS-GFP ${ }_{1-10}$ or mt-GFP $1-10$. For injections, all plasmids were diluted in Danieau solution $(58 \mathrm{mM} \mathrm{NaCl}, 0.7 \mathrm{mM} \mathrm{KCl}, 0.4 \mathrm{mM}$ MgSO4, $0.6 \mathrm{mM} \mathrm{Ca}$ (NO3)2, $5 \mathrm{mM}$ HEPES $\mathrm{pH}$ 7.6) and $0.5 \%$ phenol red. For the injections, the concentration of each plasmid was $50 \mathrm{ng} / \mathrm{ul}$. At $1 \mathrm{dpf}$, about 30 embryos were screened for fluorescence, dechorionated and anesthetized. For in vivo imaging, about one third of the injected embryos showed fluorescent signal and half were anesthetised and mounted on $35 \times 10 \mathrm{~mm}$ glass bottom Petri dishes (Ted Pella, INC. Prod. No. 14023-20) in low melting agarose (1.3\%, Euro- Clone). Fish water containing tricaine methanesulfonate $0.61 \mathrm{mM}$ (Sigma) was added in the Petri dishes, in order to keep fish anesthetized. Mounted fish were imaged at RT $\left(20-23^{\circ} \mathrm{C}\right)$ using a Leica TSC SP5 inverted confocal microscope, using a HCX PL APO ×63/numerical aperture 1.40-0.60. To image reconstituted GFP, a complete z-stack of the cell was acquired every $0.29 \mu \mathrm{m}$ and shown as Z-projection of several planes.

\section{Statistical analysis}

All of the data are representative of at least three independent experiments unless otherwise indicated. The sample was chosen by considering a power of $80 \%$, a two side alpha error of 0.05 and a beta error of 0.2. Values are expressed as mean \pm SEM. Significant differences are determined by one-way ANOVA with Dunnett's multiple comparison test for multiparametric analysis of the different groups. Student's unpaired two-tailed $t$ test was used for two experimental comparisons. All statistical analyses were performed using GraphPad Prism version 6.00 for Mac OS X, GraphPad Software, La Jolla California USA. A $p$ value $\leq 0.05$ was considered statistically significant.

\section{Acknowledgements \\ The work is supported by grants from the Ministry of University and Research (Bando SIR 2014 no. RBSI14C65Z and PRIN2017 to T.C) and from the Università degli Studi di Padova (Progetto Giovani 2012 no. GRIC128SPO to T.C., Progetto di Ateneo 2016 no. CALI_SID16_01 to T.C. and Progetto di Ateneo 2015 no. CPDA153402 to M.B.). We thank Prof. P. Pizzo (Department of Biomedical Sciences) for her support and Prof. F. Argenton and the Zebrafish Facility of the Department of Biology, University of Padova.}

\footnotetext{
Author details

'Department of Biomedical Sciences, University of Padova, Padova, Italy. ${ }^{2}$ Department of Biology, University of Padova, Padova, Italy. ${ }^{3}$ Padova Neuroscience Center (PNC), University of Padova, Padova, Italy
}

Conflict of interest

The authors declare that they have no conflict of interest.

Publisher's note

Springer Nature remains neutral with regard to jurisdictional claims in published maps and institutional affiliations. 
Supplementary Information accompanies this paper at (https://doi.org/ 10.1038/s41419-019-2092-1).

Received: 12 April 2019 Revised: 11 October 2019 Accepted: 28 October 2019

Published online: 12 November 2019

\section{References}

1. Hirsch, E. C. et al. Dopaminergic neurons degenerate by apoptosis in Parkinson's disease. Mov. Disord. 14, 383-385 (1999).

2. Spillantini, M. G. et al. Alpha-synuclein in Lewy bodies. Nature $\mathbf{3 8 8}, \mathbf{8 3 9 - 8 4 0}$ (1997). 10.1038/42166.

3. Hardy, J., Lewis, P., Revesz, T., Lees, A. \& Paisan-Ruiz, C. The genetics of Parkinson's syndromes: a critical review. Curr. Opin. Genet Dev. 19, 254-265 (2009). 10.1016/j.gde.2009.03.008.

4. Fusco, G. et al. Structural basis of synaptic vesicle assembly promoted by alpha-synuclein. Nat. Commun. 7, 12563 (2016).

5. Burre, J. et al. Alpha-synuclein promotes SNARE-complex assembly in vivo and in vitro. Science 329, 1663-1667 (2010).

6. Nemani, V. M. et al. Increased expression of alpha-synuclein reduces neurotransmitter release by inhibiting synaptic vesicle reclustering after endocytosis. Neuron 65, 66-79 (2010).

7. Larsen, K. E. et al. Alpha-synuclein overexpression in PC12 and chromaffin cells impairs catecholamine release by interfering with a late step in exocytosis. J. Neurosci. 26, 11915-11922 (2006).

8. Ma, K. L. et al. The nuclear accumulation of alpha-synuclein is mediated by importin alpha and promotes neurotoxicity by accelerating the cell cycle. Neuropharmacology 82, 132-142 (2014).

9. Kontopoulos, E., Parvin, J. D. \& Feany, M. B. Alpha-synuclein acts in the nucleus to inhibit histone acetylation and promote neurotoxicity. Hum. Mol. Genet. 15 3012-3023 (2006)

10. Schell, H., Hasegawa, T., Neumann, M. \& Kahle, P. J. Nuclear and neuritic distribution of serine-129 phosphorylated alpha-synuclein in transgenic mice. Neuroscience 160, 796-804 (2009).

11. Goers, J. et al. Nuclear localization of alpha-synuclein and its interaction with histones. Biochemistry 42, 8465-8471 (2003).

12. Shavali, S., Brown-Borg, H. M., Ebadi, M. \& Porter, J. Mitochondrial localization of alpha-synuclein protein in alpha-synuclein overexpressing cells. Neurosci. Lett. 439, 125-128 (2008)

13. Cole, N. B., Dieuliis, D., Leo, P., Mitchell, D. C. \& Nussbaum, R. L. Mitochondrial translocation of alpha-synuclein is promoted by intracellular acidification. Exp. Cell Res. 314, 2076-2089 (2008).

14. Devi, L., Raghavendran, V., Prabhu, B. M., Avadhani, N. G. \& Anandatheerthavarada, H. K. Mitochondrial import and accumulation of alpha-synuclein impair complex I in human dopaminergic neuronal cultures and Parkinson disease brain. J. Biol. Chem. 283, 9089-9100 (2008).

15. Li, W. W. et al. Localization of alpha-synuclein to mitochondria within midbrain of mice. Neuroreport 18, 1543-1546 (2007).

16. Parihar, M. S., Parihar, A., Fujita, M., Hashimoto, M. \& Ghafourifar, P. Mitochondrial association of alpha-synuclein causes oxidative stress. Cell Mol. Life Sci. 65, 1272-1284 (2008).

17. Devi, L. \& Anandatheerthavarada, H. K. Mitochondrial trafficking of APP and alpha synuclein: Relevance to mitochondrial dysfunction in Alzheimer's and Parkinson's diseases. Biochim Biophys. Acta 1802, 11-19 (2010).

18. Guardia-Laguarta, C. et al. alpha-Synuclein Is Localized to MitochondriaAssociated ER Membranes. J. Neurosci. 34, 249-259 (2014).

19. Paillusson, S. et al. alpha-Synuclein binds to the ER-mitochondria tethering protein VAPB to disrupt Ca2+ homeostasis and mitochondrial ATP production. Acta Neuropathol, 10.1007/s00401-017-1704-z (2017).

20. Chinta, S. J., Mallajosyula, J. K., Rane, A. \& Andersen, J. K. Mitochondrial alphasynuclein accumulation impairs complex I function in dopaminergic neurons and results in increased mitophagy in vivo. Neurosci. Lett. 486, 235-239 (2010).

21. Loeb, V., Yakunin, E., Saada, A. \& Sharon, R. The transgenic overexpression of alpha-synuclein and not its related pathology associates with complex I inhibition. J. Biol. Chem. 285, 7334-7343 (2010).

22. Reeve, A. K. et al. Aggregated alpha-synuclein and complex I deficiency: exploration of their relationship in differentiated neurons. Cell death Dis. $\mathbf{6}$ e1820 (2015).
23. Dauer, W. et al. Resistance of alpha -synuclein null mice to the parkinsonian neurotoxin MPTP. Proc. Natl Acad. Sci. USA 99, 14524-14529 (2002).

24. Klivenyi, $\mathrm{P}$. et al. Mice lacking alpha-synuclein are resistant to mitochondrial toxins. Neurobiol. Dis. 21, 541-548 (2006).

25. Martin, L. J. et al. Parkinson's disease alpha-synuclein transgenic mice develop neuronal mitochondrial degeneration and cell death. J. Neurosci. 26, 41-50 (2006).

26. Subramaniam, S. R., Vergnes, L., Franich, N. R., Reue, K. \& Chesselet, M. F. Region specific mitochondrial impairment in mice with widespread overexpression of alpha-synuclein. Neurobiol. Dis. 70, 204-213 (2014).

27. Ellis, C. E. et al. Mitochondrial lipid abnormality and electron transport chain impairment in mice lacking alpha-synuclein. Mol. Cell Biol. 25, 10190-10201 (2005).

28. Hsu, L. J. et al. alpha-synuclein promotes mitochondrial deficit and oxidative stress. Am. J. Pathol. 157, 401-410 (2000).

29. Guardia-Laguarta, C., Area-Gomez, E., Schon, E. A. \& Przedborski, S. A new role for alpha-synuclein in Parkinson's disease: Alteration of ER-mitochondrial communication. Mov. Disord. 30, 1026-1033 (2015).

30. Nakamura, K. et al. Direct membrane association drives mitochondrial fission by the Parkinson disease-associated protein alpha-synuclein. J. Biol. Chem. 286, 20710-20726 (2011).

31. Winslow, A. R. et al. alpha-Synuclein impairs macroautophagy: implications for Parkinson's disease. J. Cell Biol. 190, 1023-1037 (2010).

32. Calì, T., Ottolini, D., Negro, A. \& Brini, M. alpha-Synuclein controls mitochondrial calcium homeostasis by enhancing endoplasmic reticulum-mitochondria interactions. J. Biol. Chem. 287, 17914-17929 (2012).

33. Martinez, J. H. et al. Alpha-synuclein mitochondrial interaction leads to irreversible translocation and complex I impairment. Arch. Biochem. Biophys. 651, 1-12 (2018)

34. Grassi, D., Diaz-Perez, N., Volpicelli-Daley, L. A. \& Lasmezas, C. I. Palphasyn* mitotoxicity is linked to MAPK activation and involves tau phosphorylation and aggregation at the mitochondria. Neurobiol. Dis. 124, 248-262 (2018).

35. Ding, $\mathrm{H}$. et al. Asiatic acid prevents oxidative stress and apoptosis by inhibiting the translocation of alpha-synuclein into mitochondria. Front Neurosci. 12, 431 (2018).

36. Zhang, L. et al. Semi-quantitative analysis of alpha-synuclein in subcellular pools of rat brain neurons: an immunogold electron microscopic study using a C-terminal specific monoclonal antibody. Brain Res. 1244, 40-52 (2008).

37. Liu, G. et al. alpha-Synuclein is differentially expressed in mitochondria from different rat brain regions and dose-dependently down-regulates complex activity. Neurosci. Lett. 454, 187-192 (2009).

38. Ludtmann, M. H. et al. Monomeric Alpha-Synuclein Exerts a Physiological Role on Brain ATP Synthase. J. Neurosci. 36, 10510-10521 (2016).

39. Amorim, I. S. et al. Sideroflexin 3 is an alpha-synuclein-dependent mitochondrial protein that regulates synaptic morphology. J. Cell Sci. 130, 325-331 (2017).

40. Cabantous, S., Terwilliger, T. C. \& Waldo, G. S. Protein tagging and detection with engineered self-assembling fragments of green fluorescent protein. Nat. Biotechnol. 23, 102-107 (2005).

41. Cabantous, S. \& Waldo, G. S. In vivo and in vitro protein solubility assays using split GFP. Nat. Methods 3, 845-854 (2006).

42. Pedelacq, J. D., Cabantous, S., Tran, T., Terwilliger, T. C. \& Waldo, G. S. Engineering and characterization of a superfolder green fluorescent protein. Nat. Biotechnol. 24, 79-88 (2006).

43. Calì, T., Ottolini, D., Soriano, M. E. \& Brini, M. A new split-GFP-based probe reveals DJ-1 translocation into the mitochondrial matrix to sustain ATP synthesis upon nutrient deprivation. Hum. Mol. Genet., https://doi.org/10.1093/ hmg/ddu519 (2014).

44. Cieri, D. et al. Tau localises within mitochondrial sub-compartments and its caspase cleavage affects ER-mitochondria interactions and cellular $\mathrm{Ca}(2+)$ handling. Biochim. Biophys. Acta Mol. Basis Dis. 1864, 3247-3256 (2018).

45. Polianskyte, Z. et al. LACTB is a filament-forming protein localized in mitochondria. Proc. Natl Acad. Sci. USA 106, 18960-18965 (2009).

46. Hung, V. et al. Proteomic mapping of the human mitochondrial intermembrane space in live cells via ratiometric APEX tagging. Mol. Cell $\mathbf{5 5}$ 332-341 (2014).

47. Jouaville, L. S., Pinton, P., Bastianutto, C., Rutter, G. A. \& Rizzuto, R. Regulation of mitochondrial ATP synthesis by calcium: evidence for a long-term metabolic priming. Proc. Natl Acad. Sci. USA 96, 13807-13812 (1999). 
48. Ludtmann, M. H. R. et al. alpha-synuclein oligomers interact with ATP synthase and open the permeability transition pore in Parkinson's disease. Nat. Commun. 9, 2293 (2018)

49. Rizzuto, R., Simpson, A. W., Brini, M. \& Pozzan, T. Rapid changes of mitochondrial Ca2 + revealed by specifically targeted recombinant aequorin. Nature 358, 325-327 (1992).

50. Ottolini, D., Cali, T. \& Brini, M. Methods to measure intracellular $\mathrm{Ca}(2+)$ fluxes with organelle-targeted aequorin-based probes. Methods Enzymol. 543, 21-45 (2014).

51. Hoogerheide, D. P., Gurnev, P. A., Rostovtseva, T. K. \& Bezrukov, S. M. Mechanism of alpha-synuclein translocation through a VDAC nanopore revealed by energy landscape modeling of escape time distributions. Nanoscale 9, 183-192 (2017)

52. Rostovtseva, T. K. et al. alpha-Synuclein shows high affinity interaction with voltage-dependent anion channel, suggesting mechanisms of mitochondria regulation and toxicity in Parkinson Disease. J. Biol. Chem. 290, 18467-18477 (2015).

53. Abramov, A. Y., Berezhnov, A. V., Fedotova, E. I., Zinchenko, V. P. \& Dolgacheva, L. P. Interaction of misfolded proteins and mitochondria in neurodegenerative disorders. Biochem Soc. Trans, https://doi.org/ 10.1042/BST20170024 (2017).
54. Pozo Devoto, V. M. \& Falzone, T. L. Mitochondrial dynamics in Parkinson's disease: a role for alpha-synuclein? Dis. models mechanisms 10, 1075-1087 (2017).

55. Cieri, D. et al. Tau localises within mitochondrial sub-compartments and its caspase cleavage affects ER-mitochondria interactions and cellular $\mathrm{Ca}(2+)$ handling. Biochim. Biophys. Acta, https://doi.org/10.1016/j.bbadis.2018.07.011 (2018).

56. Pozo Devoto, V. M. et al. alphaSynuclein control of mitochondrial homeostasis in human-derived neurons is disrupted by mutations associated with Parkinson's disease. Sci. Rep. 7, 5042 (2017).

57. Ruan, L.et al. Cytosolic proteostasis through importing of misfolded proteins into mitochondria. Nature 543, 443-446 (2017). https://doi.org/10.1038/ nature21695.

58. Filograna, R. et al. Analysis of the catecholaminergic phenotype in human SHSY5Y and BE(2)-M17 Neuroblastoma Cell Lines upon Differentiation. PLOS ONE 10, e0136769 (2015)

59. Gavet, O. \& Pines, J. Progressive activation of CyclinB1-Cdk1 coordinates entry to mitosis. Dev. Cell 18, 533-543 (2010).

60. Brini, M. et al. Transfected aequorin in the measurement of cytosolic Ca2+ concentration ([Ca2+]c). A critical evaluation. J. Biol. Chem. 270, 9896-9903 (1995). 